\title{
Research Paper \\ Effectiveness of cognitive behavioral counseling based on acceptance and commitment therapy (ACT) for psychological flexibility in drug-abusing mothers
}

Nahid Hoseininezhad', Mahboubeh Alborzi ${ }^{\mathbf{2}}$, Peyman MamSharifi ${ }^{3}$
1. Ph.D Student of Counseling, Department of Counseling, Faculty of Education and Psychology, Alzahra University, Tehran, Iran.
2. Associate Professor of Foundations of Education Department, Faculty of Education and Psychology, Shiraz University, Shiraz,
Iran.
3. Ph.D Student of Psychology, Department of Clinical Psychology, Faculty of Psychology and Educational Sciences, Allameh
Tabataba'i University, Tehran, Iran.

Citation: Hoseininezhad N, Alborzi M, MamSharifi P. Effectiveness of cognitive behavioral counseling based on acceptance and commitment therapy (ACT) for psychological flexibility in drugabusing mothers. J of Psychological Science. 2022; 20(107): 20112025 .
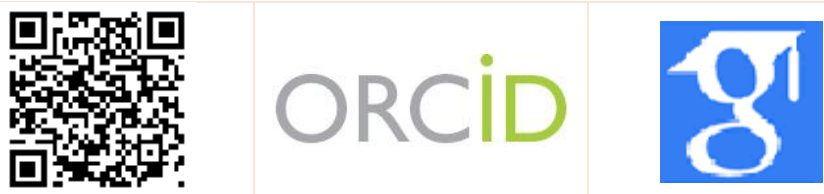

URL: https://psychologicalscience.ir/article-1-1052-fa.html

$\underline{10.52547 / J P S .20 .107 .2011}$

\section{A R T I C L E I N F O A B S T RA C T}

Keywords:

acceptance and commitment therapy, psychological flexibility, substance abuse

Received: 26 Nov 2020

Accepted: 09 Jan 2021

Available: 21 Jan 2022
Background: Today, addiction is a very important threat to the health of the family system. Cognitive-behavioral therapies with emphasis on mindfulness and attention to cognitive flexibility are effective in rehabilitation of mothers addicted to substance abuse. In this regard, the question of the present study was whether cognitive-behavioral counseling based on acceptance and commitment therapy (ACT) is effective on the psychological flexibility of mothers dependent on substance abuse? Aims: The purpose of this study was to evaluate the effectiveness of cognitive-behavioral counseling based on acceptance and commitment therapy (ACT) on psychological flexibility of mothers dependent on substance abuse.

Methods: The present study was conducted by quasi-experimental method and pretest-posttest design with a control group. The statistical population of the present study comprises those addictive mothers who have been hospitalized in the addiction treatment center of Shiraz during spring 2019. A total number of thirty addictive mothers were selected making use of available sampling. They were divided into two groups of control and experimental. Each group consisted of 15 samples. The Acceptance and Action Questionnaire of Bond et al (2007) was used as pre-test and post-test designs alike. We also employed 12-session protocol of Flaxman et al (2011) for acceptance and commitment counselling. The method of analysis of covariance was chosen to analyze collected data.

Results: The results showed cognitive-behavioral counseling which was based on acceptance and commitment therapy had effective on psychological flexibility of addictive mothers. There was a significant difference between the two groups $(\mathrm{P}<0 / 01)$.

Conclusion: According to findings, cognitive-behavioral counseling, which was based on acceptance and commitment, increases the psychological flexibility of addicted mothers.

* Corresponding Author: Mahboubeh Alborzi, Associate Professor of Foundations of Education Department, Faculty of Education and Psychology, Shiraz University, Shiraz, Iran.

E-mail: Mahboobeh.alborzi@gmail.com

Tel: (+98) 9173134319

2476-5740/ (C) 2021 The Authors. This is an open access article under the CC BY-NC-ND license

(https://creativecommons.org/licenses/by-nc/4.0/). 


\section{Extended Abstract}

\section{Introduction}

Drug abuse is one of the significant biological, psychological and social problems that is now recognized as a global problem (Anderson, 2018; Nederland and Lyons, 2018). Drug addiction is defined as a multitude of negative consequences of drug use, which are becoming more rife every day, and the world has faced astonishing statistics on the prevalence of this phenomenon in the last decade (Sohrabi, Mamsharifi, Rafezi and Aazami, 2018; Besharat, Haeri and Moghaddamzadeh, 2018). Between 162 and 324 million people worldwide have used drugs in at least the past year (Aryan et al., 2020). Although drug use and addiction are more rampant among men than women, female addicts are more vulnerable to be physical and sexual abuse than men (Sadeghi Fasaei and Jahandar Lashaki, 2020; Ghaderi, Nouri and Karimi, 2017). Moreover, due to the greater role and responsibility of women in the socialization of the new generation, addiction among women as the pillar and foundation of the family has an impact on both the family and society way more than addiction among men (Mohsenzadeh, Hashemzehi and Maadani, 2019). In addition to complications such as illness and death, women's drug use is of more significance than men's because of the potential for pregnancy and therefore the risk to their fetus (low birth weight, preterm delivery, malnutrition, miscarriage or abandoned child syndrome. Therefore, women are an important group in planning treatment for addicts (Rahimi Movaghar, Malayerikhah Langeroudi, Delbarpour Ahmadi and Amin Esmaeili, 2011).

One of the factors that can increase people's ability to fight addiction is psychological flexibility (Khodayarifard, Hejazi and Hosseininejad, 2015). Psychological flexibility refers to the ability to be in touch with the present time and to be able to change or insist on one's current behavior based on what is expected of him or her in a particular situation, a behavior that aligns with one's personal values (Wang et al., 2017).

Sharifi, Mousavi and Hassani (2018) conducted a study entitled The Diagnostic Role of the
Reinforcement Sensitivity Model, Emotional Regulation Process Strategies, and Cognitive Flexibility in Diagnosing Internet Addicts. Findings showed that negative cognitive reassessment and flexibility and activation system, inhibition system and suppression positively had the strongest relationship with the present function, respectively, and differentiated the groups from each other.

In general, cognitive flexibility, emotional regulatory process strategies, and the sensitivity of activation and inhibition systems are important factors in distinguishing Internet addicts from normal individuals. One of these interventions is treatment based on acceptance and commitment, which is considered as one of the third generation cognitivebehavioral interventions (Wayne, 2019).

The first generation cognitive therapy sessions focus too much on the client's mental arguments, which try to bring the client's thinking closer to reality by modifying and changing it from illogical to logical (Haze and Hoffman, 2017). But acceptance and commitment-based psychotherapy combined with mindfulness is an experience-based psychological intervention that uses awareness-based and acceptance-based strategies along with commitment and behavior change strategies to increase psychological flexibility (Haj Seyyed Javadi, 2019). Therefore, given the above points, counseling based on acceptance and commitment counts as a new generation of cognitive-behavioral therapies that consider increasing psychological flexibility as the goal of therapy. Despite the importance of this type of counseling, less research has been done inside Iran to confirm this claim; therefore, the aim of this study was to evaluate the effectiveness of acceptance- and commitment-based counseling on flexibility in drugaddicted mothers and the researchers sought to answer the research question of whether cognitivebehavioral counseling based on acceptance and commitment therapy (ACT) is effective on the psychological flexibility of mothers addicted to drug abuse.

\section{Method}

The methodology used by the research is quasiexperimental, pre-test and post test designs with the control group. The study population includes all drug- 


\section{Monthly Journal of Psychological Science}

addicted mothers at addiction treatment camps of Shiraz during the spring of 2020, of which 30 addicts were selected using the sampling method. They were divided into two groups: the experimental group (15 people) and the control group (15 people). The acceptance- and commitment-based behavioral cognitive counseling was held in 12 sessions within 6 weeks. Each session was held in a group and lasted 90 minutes. The prongs of the sessions of acceptanceand commitment-based behavioral cognitive counseling included: a review of the history of the problem and the formulation of the client; explanation of the acceptance and commitment therapy; reaching creative hopelessness and practicing values clarification and mindfulness; discussion of satisfaction with pain; and motivation and motivation-related activity. At the end, a retest was conducted in the second measurement.

\section{Tools}

Acceptance and Action Questionnaire: This scale was developed by Bond et al. (2007, quoted by Abbasi et al. 2012) and it has 12 items. The scale measures a construct that is about diversity, acceptance, experimental avoidance and psychological flexibility. Each item is scored on a four-point Likert scale ranging from. 1 (strongly disagree) to 5 (strongly agree). A score of 12 to 24 shows low psychological flexibility while a score of 25 to 36 indicates medium psychological flexibility and 36 to 60 is very good psychological flexibility. In the research by Abbasi et al. (2012).

The mean alpha coefficient was 0.84 and the reliability of the retest between 3 and 12 months was 0.81 and 0.79 , respectively, and in the present study the Cronbach's alpha was 0.75 .

In data analysis, in addition to calculating descriptive indices in the control and experimental groups, inferential indices were calculated by univariate analysis of covariance. Necessary calculations were performed using Spss-24 software.

\section{Results}

The mean age of the experimental group was 28 years and that of the control group was 30 years. Also, the level of education of the experimental and control groups was almost the same (high school diploma and above).

Table 1 shows the indicators of tendency toward the center and the distribution of psychological flexibility in the experimental and control groups, as well as the pre-test and post-test stages.

Table 1. Descriptive statistics of psychological flexibility between experimental and control groups in pre-test and post-test

\begin{tabular}{cccccc}
\hline \multirow{2}{*}{ Variable } & \multirow{2}{*}{ Groups } & \multicolumn{3}{c}{ Pre-test } & \multicolumn{2}{c}{ Post-test } \\
\cline { 3 - 6 } & & Mean & Standard deviation & Mean & Standard deviation \\
\hline \multirow{2}{*}{ Psychological flexibility } & Control & 14.40 & 1.68 & 16.93 & 2.52 \\
& Experimental & 14.20 & 2.07 & 26.53 & 1.92 \\
\hline
\end{tabular}

Table 1 shows the information about the mean and standard deviation of the scores of psychological flexibility of both experimental and control groups in pre-test and post-test.

The use of covariance analysis requires the observance of assumptions. Therefore, the assumptions were examined. The non-significance of Levin test in the psychological flexibility variable $(F=0.11)$ indicates that the same assumption of variance holds ( $p>0.05)$. On the other hand, the nonsignificance of the box value for the psychological flexibility variable (Box's=14.14) also indicates the homogeneity of the covariance matrix, as one of the assumptions of the analysis of covariance ( $p>0.05$ ). The Kalmogorov-Smirnov test with (statistics of 0.29 and $p<0.05)$ to evaluate the normality of the distribution of scores of psychological flexibility indicated that this variable was normal; therefore, considering the assumptions of using the analysis of covariance test, this test was used to analyze the findings.

Table 2. Analysis of covariance related to the effects of acceptance- and commitment-based counseling on psychological flexibility

\begin{tabular}{ccccccc}
\hline & Total squares & Df & Mean of squares & F & sig & Test capability \\
\hline Effect of psychological flexibility test & 0.672 & 1 & 0.672 & 0.13 & 0.72 & 0.005 \\
Intervention effect & 686.78 & 1 & 686.78 & 132.45 & 0.01 & 0.83 \\
\hline
\end{tabular}




\section{Monthly Journal of Psychological Science}

Vol. 20, No. 107, Winter(February) 2022

Given Table 2 and with emphasis on the value of $\mathrm{F}$ obtained in the source of group changes $(\mathrm{F}=132.45)$ at the level $(\mathrm{p}<0.05)$ which is in line with the effects of acceptance and commitment counseling, we can assert that acceptance- and commitment-based counseling has an impact on the psychological flexibility of drug-addicted mothers. Meanwhile, considering the means of the two groups and the amount of Eta squared, we conclude that 0.83 variance of drug-addicted mothers ' psychological flexibility is explained by the presence or absence of acceptance and commitment group counseling sessions. The analysis of the univariate covariance showed that there was a significant difference between experimental and control groups in terms of psychological flexibility.

\section{Conclusion}

The present study aimed to evaluate the effectiveness of cognitive-behavioral counseling based on acceptance and commitment (ACT) with regard to the psychological flexibility of drug-addicted mothers. The research hypothesis that acceptance and commitment-based counseling increases psychological resilience in drug-addicted mothers was confirmed. The results of this research were consistent with the results of previous studies (Ahmadian, Jedi Pour and Ahmadian, 2020; Khodayari Fard, Hejazi and Hosseini Nejad, 2015; Mendes et al., 2014; Kalantari Hormozi, Bijani and Hosseini Nejad, 2014; Kiani, Ghasemi and Poor Abbas, 2012; Petersen and Zettle, 2009).

In explaining these results, it can be acknowledged that since psychological flexibility is the goal of cognitive-behavioral therapy based on acceptance and commitment, it is expected that this type of therapy will be more effective in improving psychological flexibility than cognitive-behavioral therapy. Acceptance- and commitment-based therapy has been shown to be beneficial in drug abuse-related disorders (Thurston, Hall, Timmerman, \& Amerik, 2017).

In fact, from the perspective of acceptance and commitment therapy, all seemingly functionally different disorders share a common feature, and that is individual efforts to verify or reduce annoying personal events, which is called experimental avoidance. (Smith, Smith and Diamond, 2019). Acceptance and commitment therapy builds on the premise that avoiding certain unpleasant experiences (thoughts, feelings, and emotions) is pervasive, which is pathogenic and leads to withdrawal from treatment and overuse of narcotics (Stones, Masuda and Wilson, 2012).

In fact, drug or alcohol abuse show additional ways to avoid or escape from unpleasant personal events (Bayat and Bayat, 2015). Acceptance- and commitment-based therapy seeks to shift the goal from avoiding unpleasant emotions to the full experience of those emotions. These experiences serve to achieve valuable personal goals (Fanaei and Sajjadian, 2016).

The goal of treatment is the ability to develop acceptance-related skills to reduce avoidance and increase cognitive and behavioral flexibility. Acceptance in acceptance- and commitment-based therapy does not mean seeking unpleasant feelings and experiences and tolerating or resisting them, but it means the desire to experience anxious feelings and experiences that a person faces in the process of behavior based on their values. Thus, acceptance is opposed to experimental avoidance, which is one of the main components of psychological inflexibility (Flexman, Blackoldage and Bond, 2019).

Thus, the results of this study expand our understanding of the effectiveness of acceptance- and commitment-based counseling in drug-addicted mothers. One of the limitations of this study is the limited access to a large community of mothers suffering from drug abuse and the impossibility of selecting a random sample. The researchers recommend that a behavioral cognitive counseling program based on acceptance and commitment therapy be used by other researchers to test its effectiveness in other psychological components. It is also recommended that psychologists and counselors use this program in addiction treatment clinics to reduce drug abuse. 


\section{Monthly Journal of Psychological Science}

Ethical Considerations

Compliance with ethical guidelines: This article is taken from the first author's master thesis and submitted with the knowledge of all other authors.

Funding: This research is an independent research that has been done without the financial support of a specific organization.

Authors' contribution: The first author of this research is the main researcher. The second author of the research is the supervisor of the dissertation and the third author is the statistical analyst of the research.

Conflict of interest: There was no conflict of interest.

Acknowledgments: We sincerely thank all the officials of Shiraz addiction treatment camps who cooperated with researchers during the project. 
اثربخشى مشاوره شناختى رفتارى مبتنى بر درمان يذيرش و تعهد (ACT) بر انعطاف يذيرى روانشناختى مادران وابسته به

\title{
سوءمصرف مواد
}

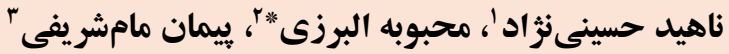

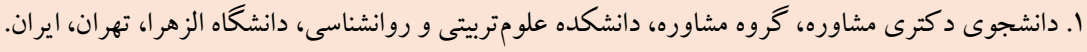

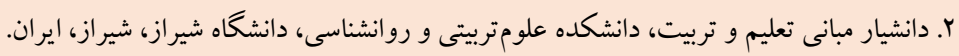

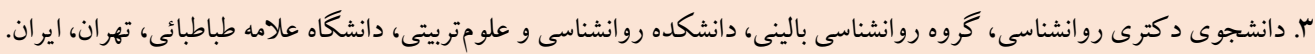

\section{جكيده}

زمينه: امروزه اعتياد يكى تهلديد بسيار مهم براى سلامت نظام خانو اده به حساب مى آيد. درمانهاى شناختى رفتارى با تأكيد بر ذهن آكاهى و توجه بر انعطاف يذيرى شناختى در بازتوانى مادران وابسته به سوءمصرف مواد مؤثر مىباشند. دراين راستا سؤال يُووهش حاضر اين بودآيا

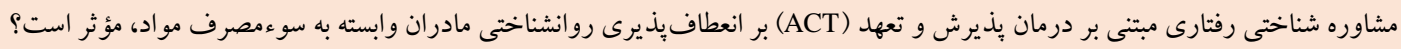

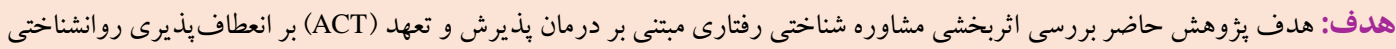

$$
\text { مادران وابسته به سوءمصرف مواد بود. }
$$

روش: يُزوهش حاضر به شيوهى شبه آزمايشى و طرح ييش آزمون - يس آزمون با گروه گواه انجام شد. جامعه آمارى اين يُزوهش مادران

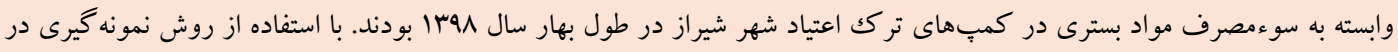

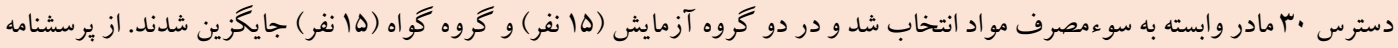

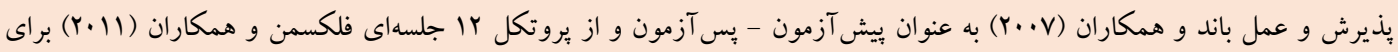

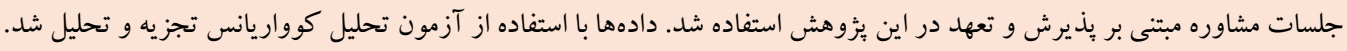
يافته ها: نتايج تحليل دادهها حاكى از آن بود كه مشاوره شناختى رفتارى مبتنى بر يذيرش و تعهد بر انعطاف يذيرى روانشناختى مادران وابسته

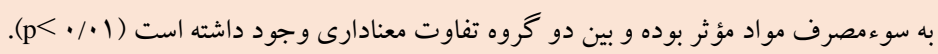

نتيجه كيرى: با توجه به نتايج اين يزوهش مشاوره شناختى رفتارى مبتى بر درمان يذيرش و تعهد، انعطاف يذيرى روانشناختى رادر مادران

$$
\text { وابسته به سوءمصرف افزايش مىدهد. }
$$

مشخصات مقاله

كليدوازمها:

درمان بذيرش و تعهل،

انعطاف يذيرى روانشناختى،

سوءمصرف مواد

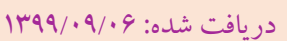

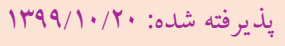

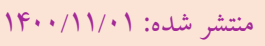

* نويسنده مسئول: محبوبه البرزى، دانشيار مبانى تعليم و تربيت، دانشكده علوم تربيتى و روانشناسى، دانشكاه شيراز، شيراز، ايران.

رايانامه: Mahboobeh.alborzi@gmail.com 
زودرس، سوءتغذيه، سقط جنين يا ايجاد سندرم ترك نوزاد) اهميت ويزه

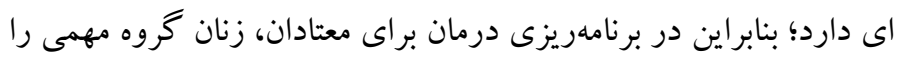

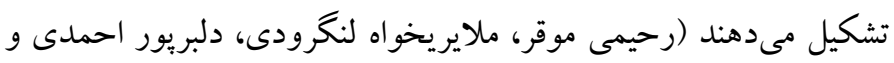

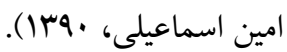
از عواملى كه مىتواند توان افراد را براى مقابله با اعتياد افزايش دهد انعطاف يذيرى روانشناختى ب است (خدايارىفرد، حجازى و حسينىنزاد،

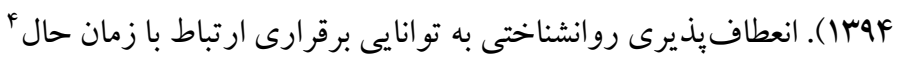

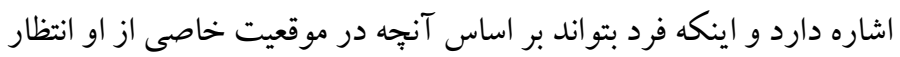

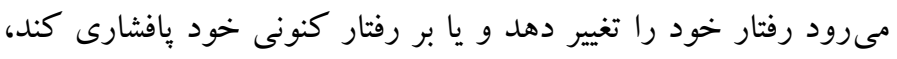
رفتارى كه با ارزشهاى شخصى او همخوانى دارد (وانگك و همكاران،

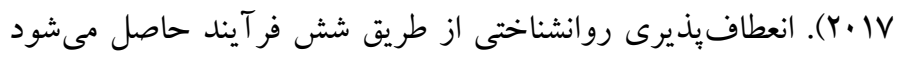

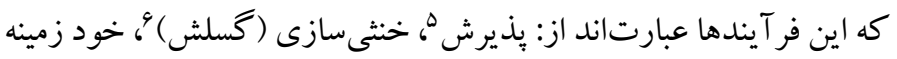

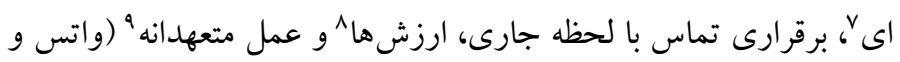

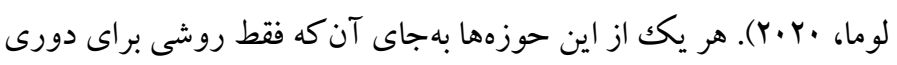
از آسيبديدگى باشند به عنوان يكك مهارت روانشناختى مثبت مفهوم

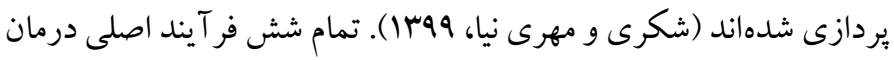

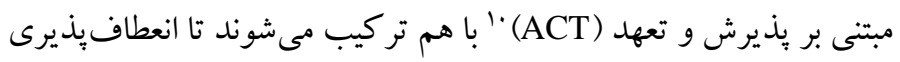

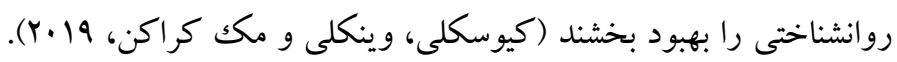
اين انعطاف يذيرى بهعنوان توانيى برقرارى ارتباط كامل با لحظه جارى

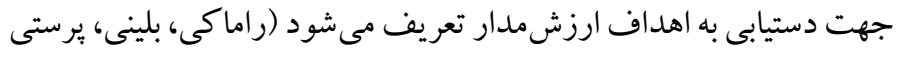
و سانتيسى، (Y) 19). كاهش سلامتروانى با انعطافنايذيرى روانى يعنى ناتوانى در وِايدارى يا تغيير رفتار جهت برآوردن اهداف ارزشمدافي بلندمدت ارتباط دارد (ياكنهام و همكاران، ·.r.r). شريفى، موسوى و حسنى (IMYV) يزوهشى با عنوان نقش تشخيصى مدل حساسيت به تقويت، راهبردهاى فر آيندى نظم جويى هيجان و انعطاف يذيرى شناختى در تشخيص افر اد داراى اعتياد به اينترنت انجام دادند. طرح يُزوهش، تابع تشخيص دو گروهى بود. جامعه يُزوهش، دانشجويان كاربر

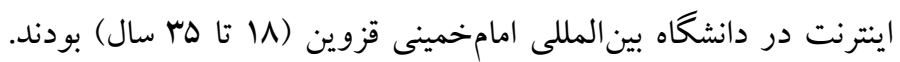

6. diffusion

7. self as context

8 . values

9. committed action

${ }^{10}$. acceptance and commitment therapy (ACT)
مقلمهـ

سوءمصرف مواد' يكى از مشكلات قابلتوجه زيستى، روانى و اجتماعى است كه امروزه بهعنوان معضلى جهانى شناخته مى شود (اندرسون، 1) +Y؛ ندرلند و ليونز، \| · Y). اعتياد به مواد مخدر بهصورت انبوهى از بيامدهاى منفى ناشى از مصرف عنوان مىشود كه اين بيامدها هر روز شيوع بيشترى ييدا مى كنند و جهان با آمار حيرت آور شيوع اين يديده، در دهئ اخير روبرو بوده است (سهر ابى، مامشريفى، رافضى و اعظمى، لVIr! بشارت، حايرى و مقدمزاده، IM IV ). سوء مصرف به الكوى غير انطباقى از مصرف مواد كفته مىشود كه منجر به مشكلات مكرر و عوارض سوء مى گردد (انجمن روانيزشكى آمريكا، سا ·Y)؛ به عبارت ديخً؛ از ديد كاه آسيب شناسانه، هر مادهاى كه بعد از مصرف، فرد رادجار تغيير اتى نمايد كه كاركردهاى اجتماعى و فردى وى را مختل كند و اجتماع نيز نسبت به آن حساسيت داشته باشد، مخدر است و شخصى كه جِنين موادى را مصرف مى كند، معتاد ` محسوب مى كردد (مامشريفى، كورانى، در تاج، حقمحمدى شر اهى و سهى، 99ب1). از سوى ديكر، سوءمصرف مواد يكى از مشكلات عصر حاضر است كه زندگى ميليونها انسان را ويران نموده و سرمايههاى كلان ملى را صرف مبارزه يا جبران صدمات ناشى از آن مى كند (كرمى و

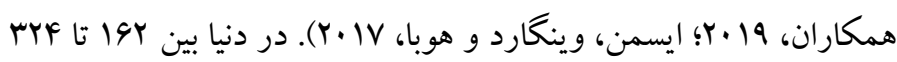
ميليون نفر انواع مواد مخدر را حداقل در يكك سال كذشته مصرف كردهاند

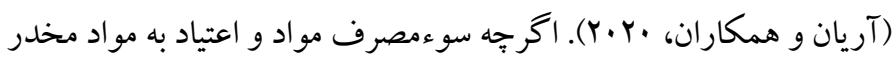
در مردان بيشتر از زنان است، اما احتمال سوءاستفادههاى جسمى و جنسى در زنان معتاد بيشتر از مردان است (صادقى فسايى و جهاندار لاشكى، 9هץ|؛ قادرى، نورى و كريمى، وهب1). علاوه بر اين، به دليل نقش و مسئوليت بيشتر زنان در جامعه يذيرى نسل جديد، اعتياد زنان بهعنوان ركن و اساس خانواده تأثيرى فراتر از اعتياد مردان بر خانواده و جامعه مىنهد (محسنزاده، هاشمزهى و معدنى، ^هب| ). مصرف مواد در زنان نسبت به مردان افزون بر عوارضى مانند بيمارى و مرگگ، به دليل احتمال حاملكى و بنابراين در خطر قرار گرفن جنين آنان (تولد نوزاد با وزن كم، زايمان

\footnotetext{
1. Substance abuse

${ }^{2}$. addicted

${ }^{3}$. psychological flexibility

${ }^{4}$. contact with present moment

${ }^{5}$. acceptance
} 
همكاران، 19.Y). جلسات شناخت درمانى نسل اول تمركز بيشازحد مشاور بر روى استدلالهاى ذهنى مراجع است كه با اصلاح و تغيير آن از غيرمنطقى به منطقى، سعى بر نزديك سازى تفكر مراجع با واقعيت دارد (هيز و هافمن، Y. IV)؛ اما رواندرمانى مبتنى بر بذيرش و تعهد همراه با ذهن آكاهى ' يكك مداخله روانشناختى مبتنى بر تجربه است كه راهبردهاى

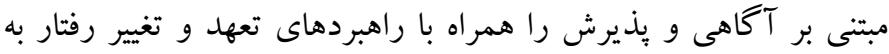

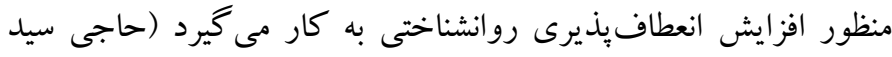

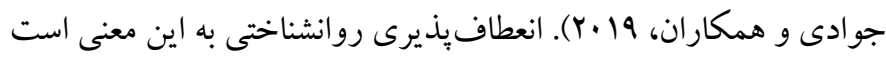
كه فرد بهطور كامل با لحظات كنونى تماس داشته و بر اساس مقتضيات وضعيتى كه در آن قرار دارد متعهد شود كه رفتار خود راد در راستاى ارزش

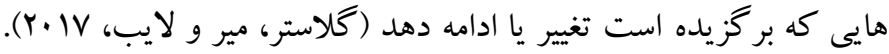

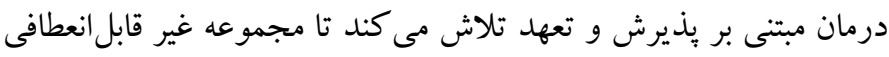

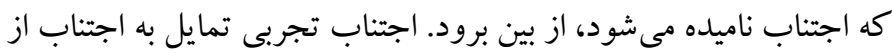
خاطر ات، عواطف و افكار ناخوشايند و ساير تجارب فردى است (اسميث،

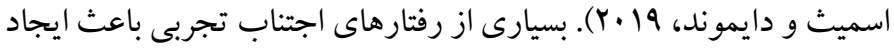
آسيب جسمى مى شوند يا مشكلات ايجاد شده در وهله اول را وخيمتر

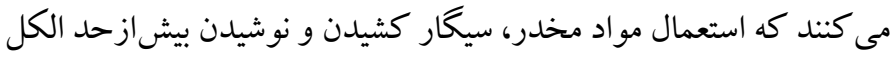

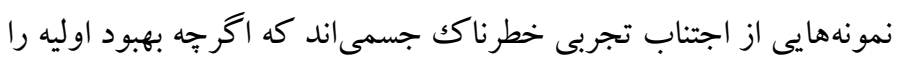
دارند اما باعث وخيم تر شدن مشكلات مى شوند و باعث مى شوند نتوانيم از يكك زندگى معنى دار، هدفمند و سرزنده برخو ردار شويم (فلكسمن،

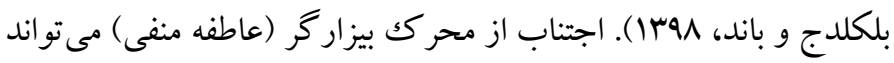

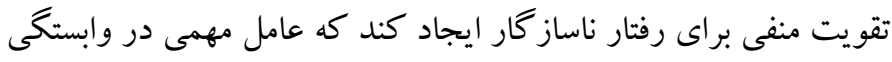

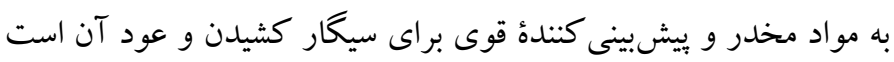

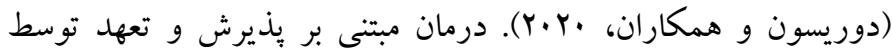

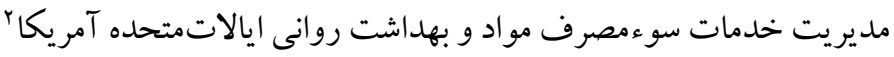
(Y Y (Y در ثبت ملى خود در برنامهاو و شيوههاى مبتنى بر شواهد به رسميت

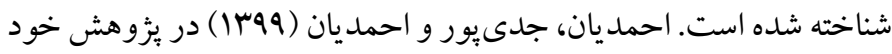
به اين نتيجه دست يافتند كه درمان مبتنى بر بذيرش و تعهد بيشتر از درمان

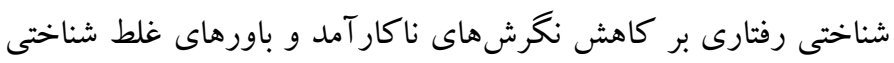

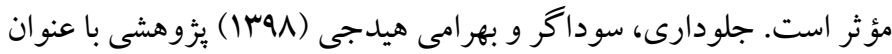

2. United States Substance Abuse and Mental Health Service Administration (SAMHSA)
انتخاب نمونه با روش نمونه گيرى در دسترس صورت يذيرفت. نمونهى

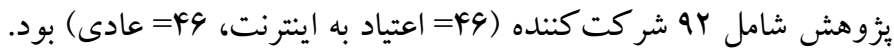

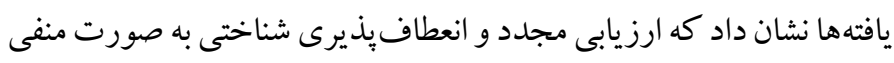
و سيستم فعالساز، سيستم بازدارى و فرونشانى به صورت مثبت به ترتيب

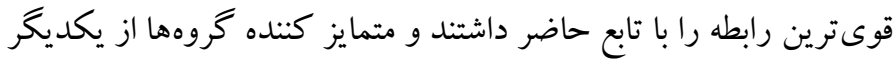
بودند. به طور كلى، انعطافيذيرى شناختى، راهبردهاى فر آيندى نظم

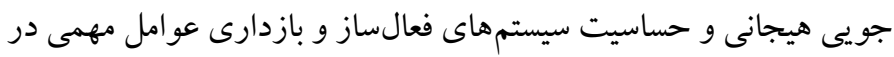

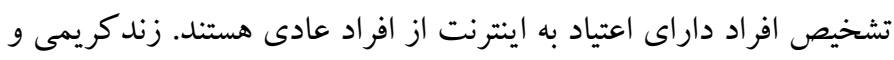

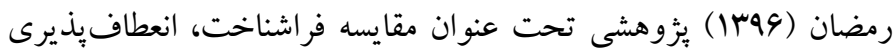
شناختى و توجه متمركز در افراد وابسته به متامفتامين و افراد سالم انجام

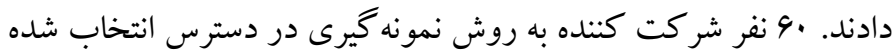

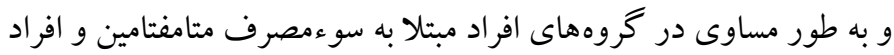

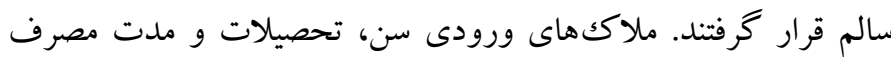

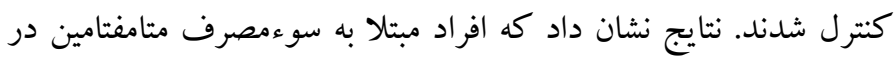
فراشناخت، انعطافيذيرى شناختى و توجه متمركز به ميزان معنىدارى ضعيفتر از افراد سالم هستند. همجِنين، بيشترين تفاوت در ميزان فراشناخت و سبس در توجه متمر كز بين دو گروه بود. طبق يافتهاى بدست

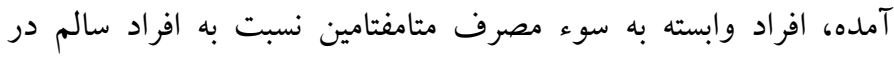
كاركردهاى اجرايى ضعف عملكردى معنىدارى نشان مىدهند. دانگك،

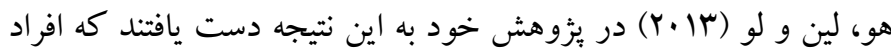
مبتلا به اختلال اعتياد به اينترنت نسبت به افراد سالم در موقعيت جابجايى ذهنى دشوار به آسان، فعالسازى مغزى بيشترى رادر اينسولاى دوجانبه و در موقعيت جابجايى ذهنى آسان به دشوار نيز فعالسازى مغزى بيشترى را لراس در بر كانئوس دوجانبه نشان مىدهند كه اين نيز دلالت بر كاهش انعطاف يذيرى شناختى بيشتر در اين افراد دارد؛ بنابراين، كاهش انعطافيذيرى شناختى به دليل ايجاد مشكل در تغيير و جابجايى ذهنى منابع توجهى و شناختى مى تواند موجب تمركز متورم و افراطى فرد بر استفاده از اينترنت و ويزگ گىهاى تقويت كنندهى آن شود.

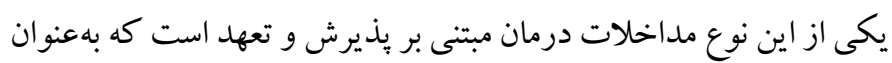

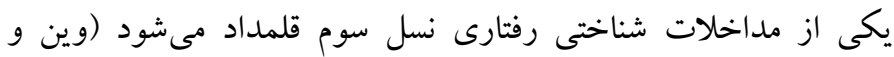
1. mindfulness 
رفتارى در درمان زنان زندانى مبتلا به سوءمصرف مواد با ل1 ماه بيخيرى نتايج نشان داد كه در زمينه اختلالات روانى و اجتناب در شر كت كنند كان

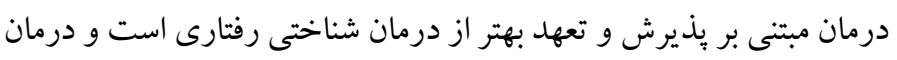

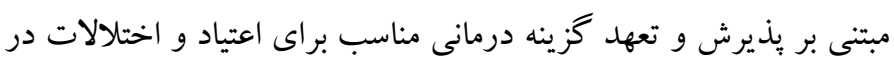
زنان زندانى است.

بنابراين با توجه به مطالب مذكور مشاوره مبتنى بر يذيرش و تعهد نسل

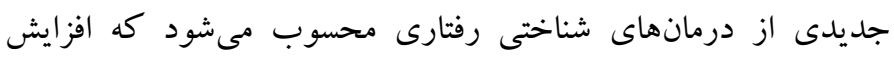
انعطاف يذيرى روانشناختى را هدف درمانى خود مى داند. على غم اهميت

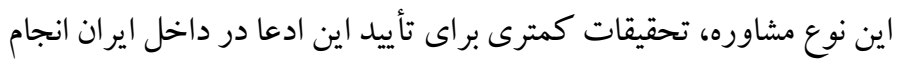

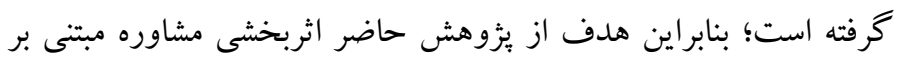
يذيرش و تعهل بر انعطاف يذيرى در مادران وابسته به سو ءمصرف مو اد است

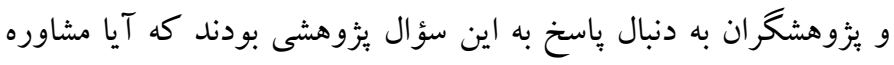

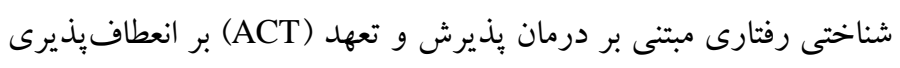

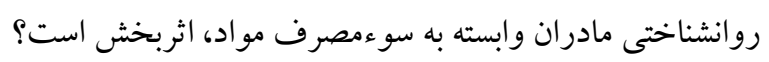

روش الف) طرح ئولهش و شركت كنند كان: روش ئزوهش از نوع شبه

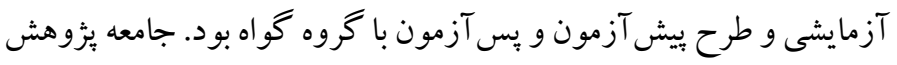

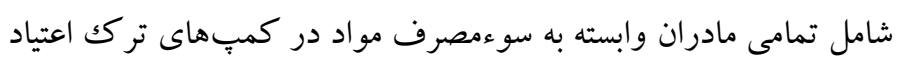

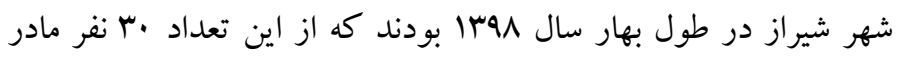

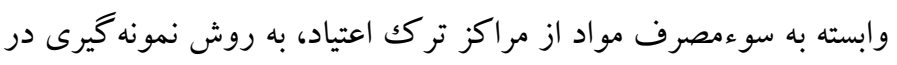

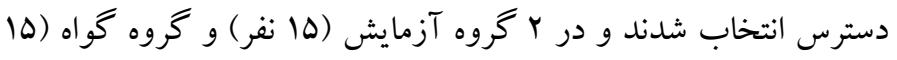

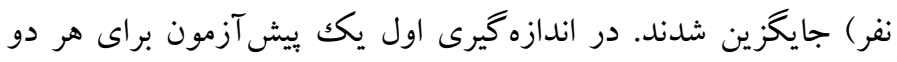

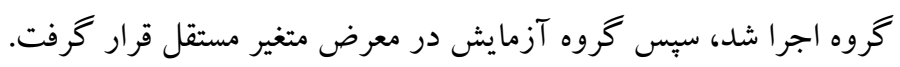

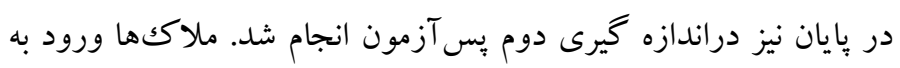

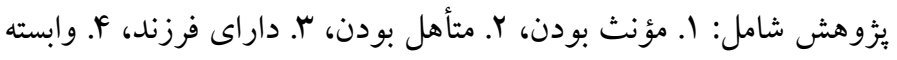

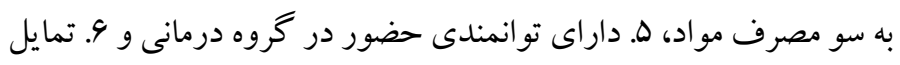
به همكارى در بزوهش بود. ملاكك خروج از يزوهش نيز عدم تمايل به

$$
\text { ادامه شر كت در يثزوهش بود. }
$$

مشاوره شناختى رفتارى مبتنى بر بذيرش و تعهد در با جلسهُ شش هفتهاى

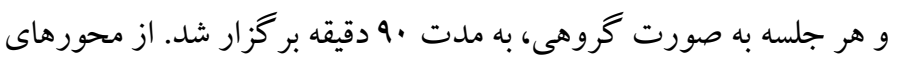

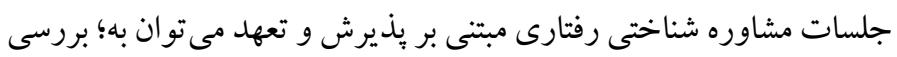

اثربخشى درمان مبتى بر يذيرش و تعهل بر انعطاف يذيرى روانشناختى و

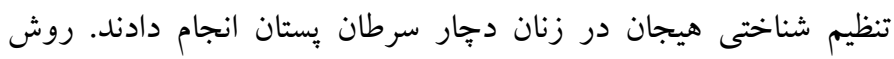

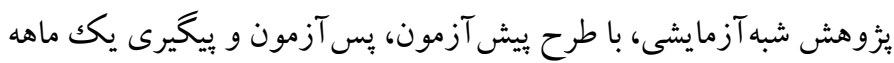

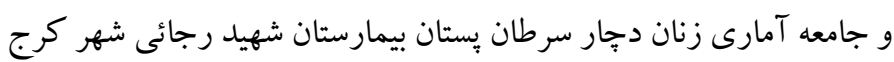

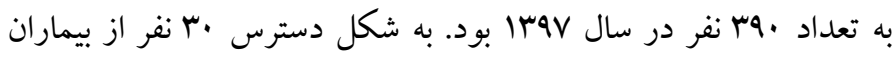

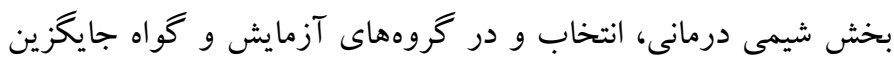

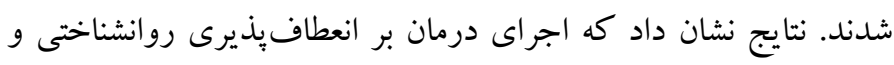

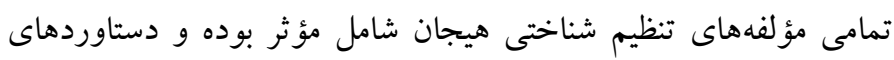

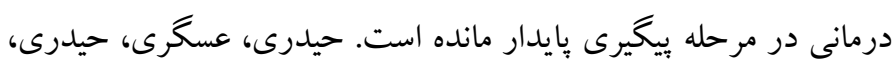

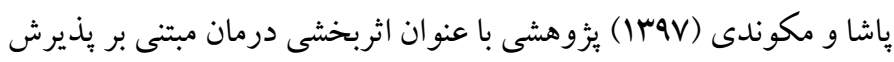

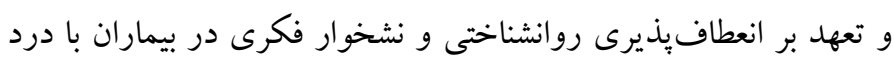

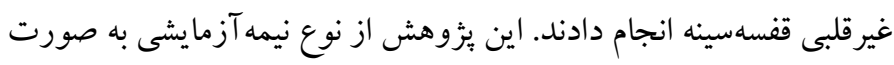

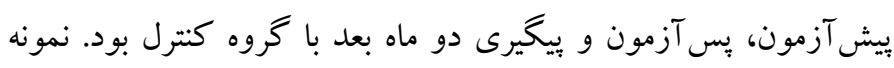

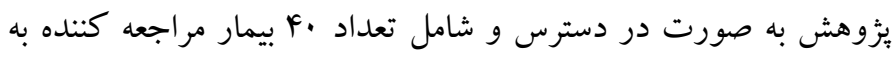

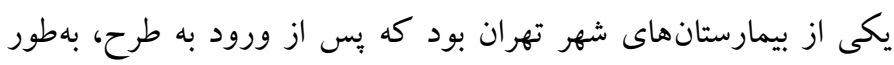

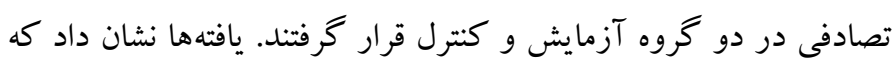

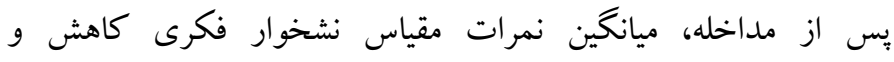

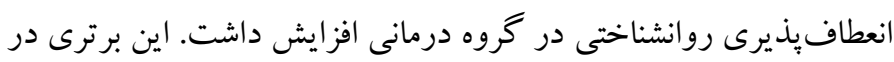
ييكيرى دو ماه بعد نيز حفظ شده بود. اوركى، جهانى و رحمانيان (ITQVV)

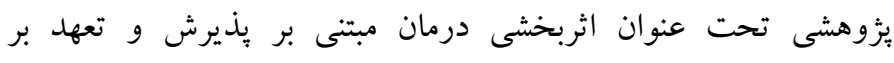

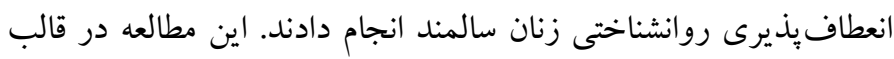
يُروهشى نيمه آزمايشى باطرح بيش آزمون - يس آزمون - يِيخيرى انجام

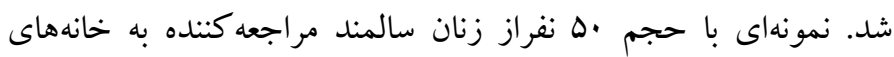

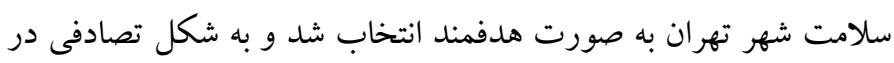

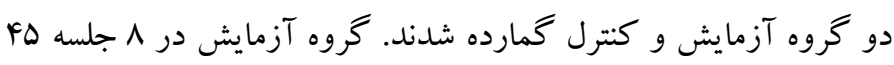

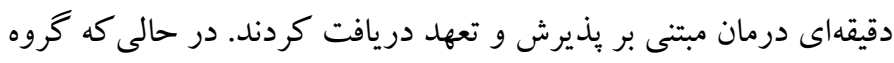

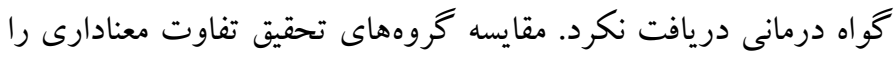

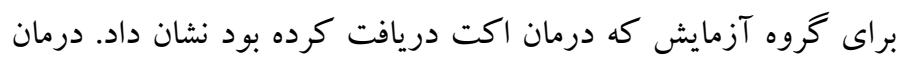
مبتنى بر يذيرش و تعهد منجر به افزايش معنىدار در انعطافيذيرى

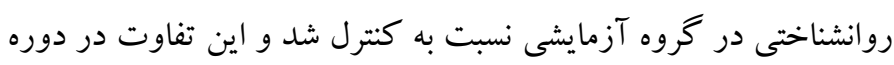

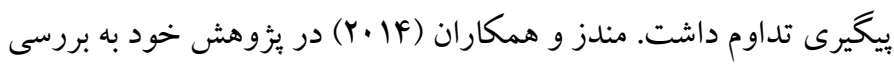

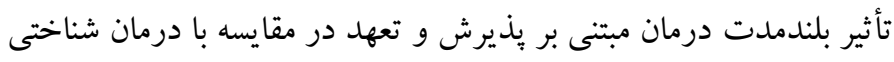


مى دهد. ميانگين و انحر اف استاندارد نمرات انعطاف يذيرى روانشناختى در

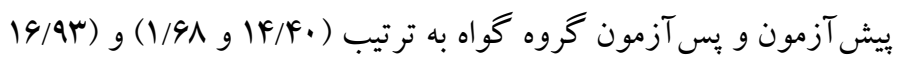

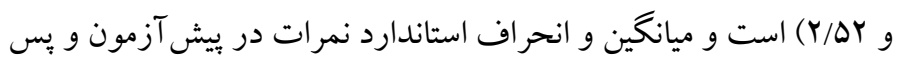

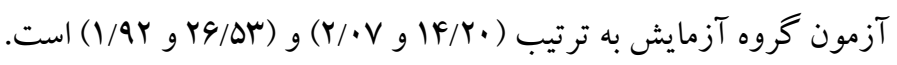
از آنجا كه استفاده از تحليل كوواريانس نيازمند رعايت مفروضهها است لذا مفروضههاى آن مورد بررسى قرار كرفت. عدم معنادارى آزمون لوين در متغير انعطاف يذيرى روانشناختى (II/ = F=)، نشان مى (I) كه مفروضه يكسانى واريانسها برقرار است (ه • • • (p). از سوى ديخر عدممعنادارى

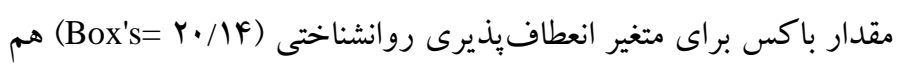
نشاندهنده همسانى ماتريس كوواريانس ها، به عنوان يكى از مفروضات آزمون تحليل كوواريانس برقرار است (ه • • >p). آزمون كالمو گروف اسميرنوف با (آماره هץ/• و ه •> > > براى بررسى نرمال بودن توزيع نمرات انعطاف يذيرى روانشناختى حاكى از نرمال بودن اين متغير بود؛ بنابراين با توجه به رعايت مفروضههاى استفاده از آزمون تحليل كوواريانس، براى تحليل يافته از اين آزمون استفاده شد
تاريخجه مشكل و فرمولبندى مراجع، توضيح فلسفه درمان (ACT)؛ رسيدن به ناميدى خلاق و تمرينات شفافسازى ارزش ها و ذهن آكاهى، بحث ييرامون رضايت از رنج، ايجاد انخيزه و فعاليت معطوف به انگيزه اشاره كرد. در يايان نيز در اندازه گيرى دوم يس آزمون انجام شد. ملاحظات اخلاقى يثوهش حاضر به شرح ذيل بودند: ا. كليه ياسخدهندها بهصورت كتبى اطلاعاتى در مورد يزوهش دريافت كرده و در صورت تمايل در يثزوهش مشاركت مىنمودند. Y. اين اطمينان به آزمودنىها داده شد كه تمام اطلاعات محرمانه هستند و براى امور يثوهشى مورد استفاده قرار

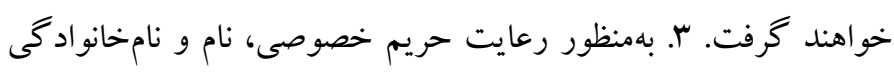

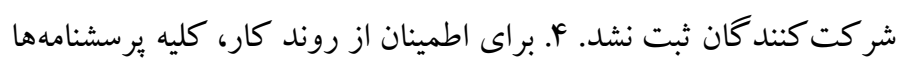
توسط خود بثزوهش كر اجرا شد.

بافْته جدول الاطلاعات مربوط به ميانگين و انحراف معيار نمرات انعطاف يذيرى

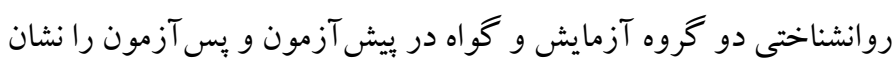

\begin{tabular}{|c|c|c|c|c|c|}
\hline \multicolumn{3}{|c|}{ يس آزمون } & \multicolumn{2}{|c|}{ ي بيش آزمون } & \multirow{2}{*}{ متغير } \\
\hline انحراف استاندارد & ميانگين & انحراف استاندارد & ميانگين & كروهاهl & \\
\hline$r / \Delta r$ & $19 / 94$ & $1 / 91$ & $\mid f / F$. & كواه & \multirow{2}{*}{ انعطاف يذيرى روانشناختى } \\
\hline $1 / 9 r$ & rq/QT & $r / \cdot V$ & $\mid F / Y$. & آزمايش & \\
\hline
\end{tabular}

جدول r. تحليل كوواريانس موتبط با بررسى اثرات مشاوره مبتنى بر يذيرش و تعهد بر انعطاف يذيرى روانشناختى

\begin{tabular}{|c|c|c|c|c|c|c|}
\hline 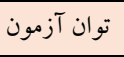 & sig & $\bar{F}$ & ميانگين مجذورات & درجهُ آزادى & مجموع مجذورات & \\
\hline$\cdot \% \Delta$ & $\cdot / N r$ &.$/ 14$ & $.19 V r$ & 1 &.$/ 9 V r$ & اثر يِش آزمون انعطاف يذيرى روانشناختى \\
\hline . &.$/ 1^{*}$ & $\mid r r / F \Delta$ & GNG/VA & 1 & $919 / \mathrm{VA}$ & اثر مداخله \\
\hline
\end{tabular}

تكك متغيرى نشان داد كه بين گ ووههاى آزمايش و گواه از لحاظ انعطاف يذيرى روانشناختى تفاوت معنادارى وجود دارد.

\section{بحث و نتيجه تيرى}

هدف از انجام اين يثزوهش بررسى اثربخشى مشاوره شناختى رفتارى مبتنى بر يذيرش و تعهد (ACT) بر انعطاف يذيرى روانشناختى مادران وابسته به سو مصروف مواد بود. فرضيه بيزوهش مبنى بر اينكه مشاوره مبتنى بر يذيرش برش و تعهد باعث افزايش انعطافيذيرى روانشناختى در مادران وابسته به
با توجه به جدول Y و با تأكيد بر مقدار F به دست آمده در منبع تغييرات كروه (ه/F/ مبتنى بر يذيرش و تعهد مى بردازد مى توان مطرح نمود كه مشاوره مبتنى بر پذيرش و تعهد بر انعطاف يذيرى روانشناختى مادران مبتلا به سوءمصرف مواد مؤثر بوده و با ملاحظه ميانگينهاى دو گروه و مقدار مجذور اتا، به اين نتيجه مىرسيم كه شی/• واريانس انعطاف يذيرى روانشناختى مادران وابسته به سوءمصرف مواد، از طريق حضور يا عدم حضور در جلسات مشاوره گرووهى مبتنى بر يذيرش و تعهد تبيين مى گردد. تحليل كوواريانس 
اين امر بيمارىزا است و منجر به تركك درمان و مصرف بيشتر مواد مىشود

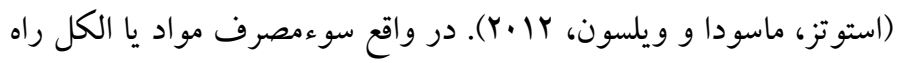

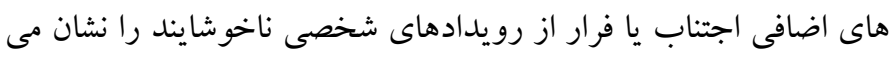

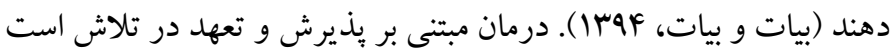
تا هدف را از اجتناب هيجانات ناخوشايند به تجربه كامل اين هيجانات تغيير دهد. اين تجربيات در خدمت رسيدن به اهداف ارزشمند شخصى است

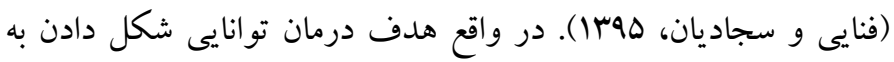

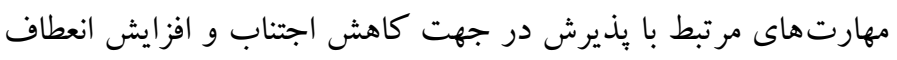
يذيرى شناختى و رفتارى است. يذيرش در درمان مبتنى بر بذيرش و و تعهد به معناى خواستن احساسات و تجارب ناخوشايند و تحمل يا مقاومت در برابر آنها نيست، بلكه به معناى تمايل جهت تجربه كردن احساسات و و تجارب اضطراب آورى است كه فرد در فر آيند رفتار بر اساس ارزشهاى نهاى

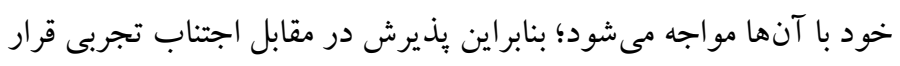

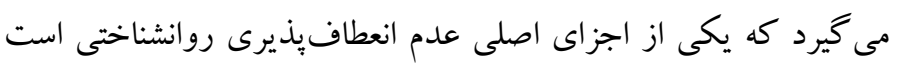

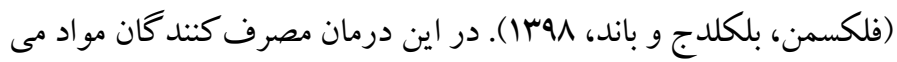
توانند تجربيات خود را بيذيرند و تحمل خود را افزايش دهند و به همان ميزان از تجربيات قبلى و افكار مصرف خود فاصله بخيرند. در حقيقت،

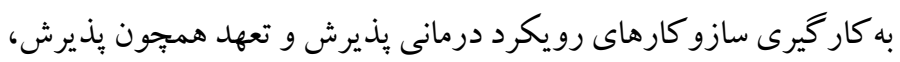

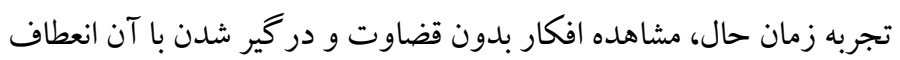
يذيرى را افزايش مىدهد و اين امر توانايى فرد را براى كنار آمدن با افكار

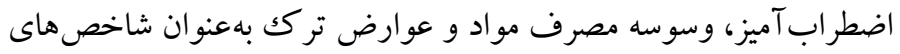
اصلى در تداوم مصرف، افزايش مىدهد. با توجه به ماهيت و هدف مشاوره

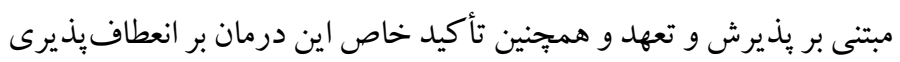
روانشناختى، به نظر قابل توجيه است كه مشاوره مبتنى بر بذيرش و و تعهد

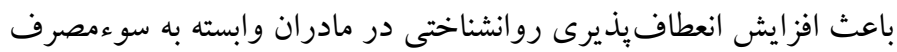
مواد شود. بدين ترتيب، نتايج اين بثروهش شناخت ما را از اثربخشى مشاوره مبنى بر

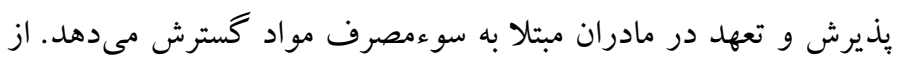
محدوديتهاى اين يزوهش مىتوان به محدوديت دسترسى به جامعه

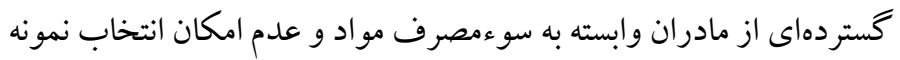
تصادفى اشاره كرد. محققان ييشنهاد مى كنند كه برنامه مشاوره شناختى
سوءمصرف مواد مىشود، مورد تأييد قرار گرفت. نتايج اين يزوهش با نتايج

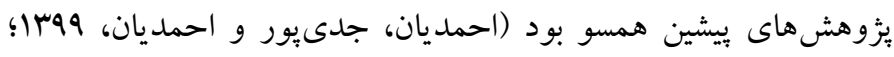

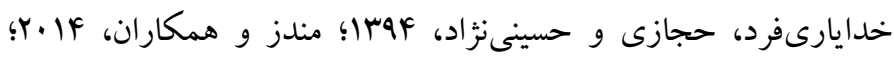

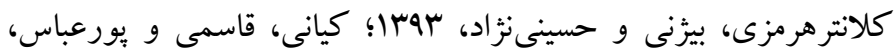

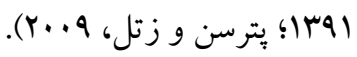
احمديان، جدى يور و احمديان (199) در بئوهش خود به اين نتيجه رسيدند كه درمان مبتنى بر يذيرش و تعهل بيشتر از درمان شناختى - رفتارى

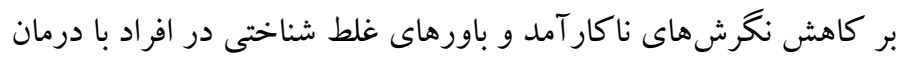

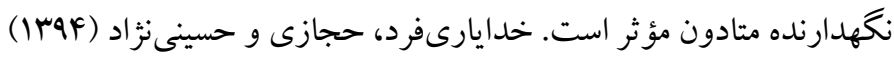
در ثروهش خود به اين نتيجه دست يافتند كه مشاوره شناختى رفتارى مبتى

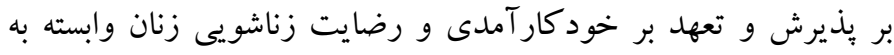

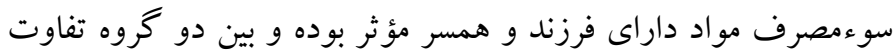

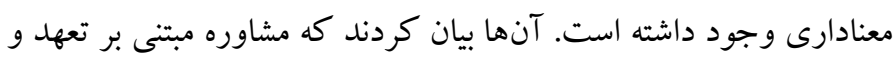
بذيرش، خودكار آمدى و رضايت زناشويى را در زنان وابسته به سوءمصرف مواد داراى فرزند و همسر افزايش مىدهد. يترسن و زتل

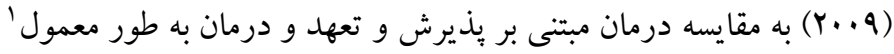

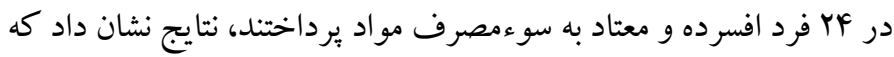

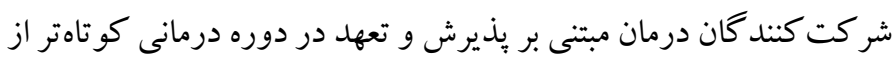
همتايان خود بهبود يافتند. در تبيين اين نتايج مىتوان اذعان كرد كه از آنجايى كه انعطافيذيرى روانشناختى هدف درمان شناختى رفتارى مبتى بر بذيرش و تعهد است، اثربخشتر بودن اين نوع از درمان در بهبود انعطاف يذيرى روانشناختى راه بـا، نسبت به درمان شناختى رفتارى صرف انتظار مىرود. درمان مبتنى بر بر بردي

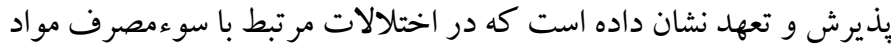

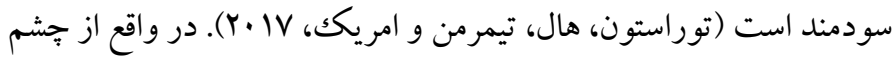
انداز درمان مبتنى بر بذيرش و تعهد تمامى اختلالات به ظاهر متفاوت به

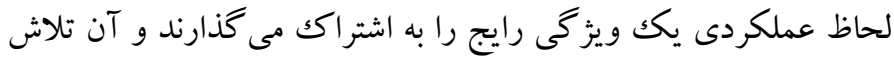

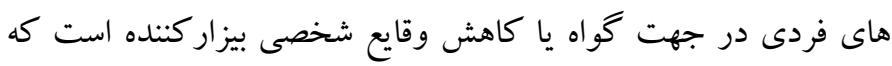

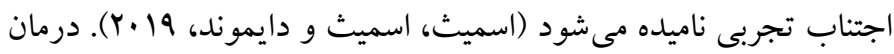
مبتى بر يذيرش و تعهد بر اين فرض عمل مى كند كه اجتناب از تجارب

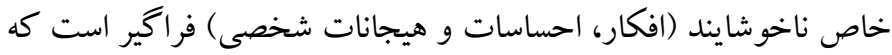

1. Treatment As Usual (TAU) 
حامى مالى: يُوهش حاضـر يزوهشسى مسـتقل بوده كه بدون حمايت مالى سـازمان خاصى صورت گرفته است. نقش هر يكك از نويسند كان: نويسنده اول اين يثوهش محقق اصلى است. نويسنده دوم يزوهش استاد راهنماى باياننامه و نويسنده سوم تحليل گر آمارى يزوهش است. تضاد منافع: تضاد منافعى وجود نداشت.

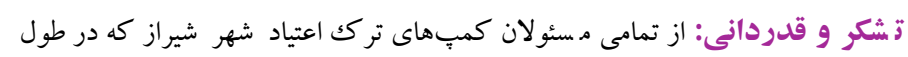
يروزه با يُزوهشخران همكارى داشتند صميمانه تشكر مى هود.
رفتارى مبتنى بر درمان بذيرش و تعهد توسط ساير محققان براى آزمون

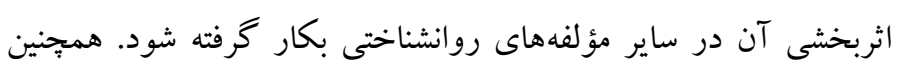

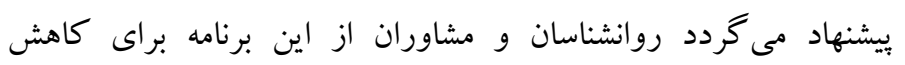
سوءمصرف مواد در كلينيك هاى تر كك اعتياد استفاده نمايند.

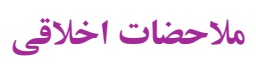

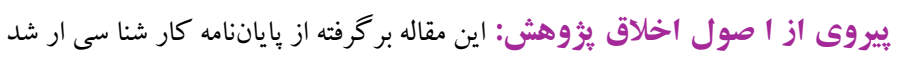
نويسنده اول است و با آكاهى همهى نويسند آحان ديخر ارسال شده است. 


\section{References}

Abasi, E., Fti, L., Molodi, R., \& Zarabi, H. (2012). Psychometric properties of Persian Version of Acceptance and Action Questionnaire II. Psychological Methods and Models, 2(10), 6580. (Persian). [Link]

Ahmadian H, Jedipour S, \& Ahmadian H. (2020). Comparison of the Effectiveness of CognitiveBehavioral Therapy and Acceptance and Commitment Therapy on Reducing Dysfunctional Attitudes and Cognitive Misconceptions in People with Methadone Maintenance Treatment. Etiadpajohi, 14 (56), 287-312. (Persian). [Link]

American Psychiatric Association. (2013). Avoidant personality disorder. In Diagnostic and statistical manual of mental disorders (5th ed). [Link]

Andersen, S. L. (2018). Stress, sensitive periods, and substance abuse. Neurobiology of stress, 10, 100140. [Link]

Aryan, N., Banafshe, H. R., Farnia, V., Shakeri, J., Alikhani, M., Rahimi, H., Sehat, M., Mamsharifi, P., Ghaderi, A., \& Omidi, A. (2020). The therapeutic effects of methylphenidate and matrixmethylphenidate on addiction severity, craving, relapse and mental health in the methamphetamine use disorder. Substance abuse treatment, prevention, and policy, 15(1), 72. [Link]

Bayat, F., \& Bayat, L. (2016). Structural Relations of the Tendency to Drug Abuse and Behavioral Inhibition/Activation Systems: Mediating Role of Personality Traits, Alexithymia and Attachment Styles. Journal of Research in Psychological Health, 9(4), 47-61. (Persian). [Link]

Besharat, M., Hayeri, M., \& Moghadamzade A. (2018). Predicting role of alexithymia and perceived social support in medicinal, motivational and combined (medicinal-motivational) treatment of substance abuse. The Journal of Psychological Science, 17(65), 21-45. (Persian). [Link]

Daniels, J., Netherland, J. C., \& Lyons, A. P. (2018). White Women, U.S. Popular Culture, and Narratives of Addiction. Contemporary Drug Problems, 45(3), 329-346. [Link]

Dong, G., Hu, Y., Lin, X., \& Lu, Q. (2013). What makes Internet addicts continue playing online even when faced by severe negative consequences? Possible explanations from an fMRI study. Biological Psychology, 94, 282-289. [Link]

Dorison, C. A., Wang, K., Rees, V. W., Kawachi, I., Ericson, K., \& Lerner, J. S. (2020). Sadness, but not all negative emotions, heightens addictive substance use. Proceedings of the National Academy of Sciences of the United States of America, 117(2), 943-949. [Link]

Eiseman, S., Wingard, J. A., \& Huba, G. J. (2017). Drug abuse: Foundation for a psychosocial approach. Routledge Press. [Link]

Fanaei, S., \& Sajjadian, I. (2016). The Effectiveness of Acceptance and Commitment Therapy on Experiential Avoidance in Overweight Individuals. Journal of Research in Behavioural Sciences, 14(2), 146-153. (Persian). [Link]

Flexman, P. E; Blackcledge, J. T., \& Frank, B. (2011). Acceptance and commitment-based therapy: Distinctive features of cognitive and behavioral therapy. Translated by Mohammad Khodayari Fard and Nahid Hosseini Nejad (2019). Tehran: University of Tehran Press. (Persian). [Link]

Garami, J., Valikhani, A., Parkes, D., Haber, P., Mahlberg, J., Misiak, B., Frydecka, D., \& Moustafa, A. A. (2019). Examining Perceived Stress, Childhood Trauma and Interpersonal Trauma in Individuals With Drug Addiction. Psychological Reports, 122(2), 433-450. [Link]

Ghaderi, S., Nouri, R., Karimi, J. (2017). Etiology of Women's addiction (A Comparative Study). Journal of Social Problems of Iran, 8(1), 139-162. (Persian). [Link]

Gloster, A., Meyer, A., \& Lieb, R. (2017). Psychological flexibility as a malleable public health target: Evidence from a representative sample. Journal of contextual behavioral science, 6, 166-171. [Link]

Haji Seyed Javadi, T., Aghareb Parast, N., Shahsavani, S., Chehraghi, M. J., Razavi, L., Rahmani, S., \& Nejati, S. (2019). Comparison of the Effectiveness of Mindfulness-Based Stress Reduction Group Therapy With Acceptance and Commitment Therapy on Severity of Pain and Health-Related Quality of Life in Patients With Migraine. International Clinical Neuroscience Journal, 6(3), 111-117. [Link]

Hayes, S. C., \& Hofmann, S. G. (2017). The third wave of cognitive behavioral therapy and the rise of processbased care. World psychiatry: official journal of the World Psychiatric Association (WPA), 16(3), 245246. [Link]

Heidari, F., Asgari, P., Heidari, A., Pasha, R., \& Makvandi, B. (2018). The Effectiveness of acceptance and commitment therapy on psychological flexibility and rumination in patients with non-cardiac chest pain. Middle Eastern 
Journal of Disability Studies, 8, 46-46. (Persian). [Link]

Jelodari, S., Sodagar, S., \& Bahrami Hidaji, M. (2020). The effectiveness of Acceptance and Commitment Therapy (ACT) on psychological flexibility and cognitive emotion regulation in women with breast cancer. Journal of Applied Psychology, 13(4), 527548. (Persian). [Link]

Kalantar Hormoz, A., Bijani, J., \& Hossaini Nejad, N. (2015). Effectiveness of cognitive-behavioral group therapy on self-efficacy and self-esteem in substance-Abusing Spouses. Journal of Counseling Research, 13 (52), 91-108. (Persian). [Link]

Kioskli, K., Winkley, K., \& McCracken, L. (2019). Might psychological flexibility processes and Acceptance and Commitment Therapy (ACT) apply in adults with painful diabetic neuropathy? A cross-sectional survey. Journal of contextual behavioral science, 13, 66-73. [Link]

MamSharifi P, Koorani Z, Dortaj F, Haghmohamadi Sharahi G, Sohi M. Addiction prone prediction modeling based on meta-cognitive beliefs and sensation seeking: the mediating role of big five personality traits. The Journal of Psychological Science, 19(94), 1219-1230. (Persian). [Link]

Menéndez, A. G., García, P. F., Lamelas, F. R., \& Lanza, p. V. (2014). Long-term outcomes of Acceptance and Commitment Therapy in drug-dependent female inmates: A randomized controlled trial. International Journal of Clinical and Health Psychology, 14 (1), 18-27. [Link]

Mohsenzadeh, T., hashemzehi, N., \& Madani, S. (2019). Sexuality Social Factors on the needs of addicted women for treatment) (Analysis of the narratives of women staying for the Recovery centers in Tehran province). Women and Family Studies, 12(43), 105123. (Persian). [Link]

Oraki, M., Jahani, F., \& Rahmanian, M. (2018). The effectiveness of acceptance and commitment therapy (ACT) on the psychological flexibility of the elderly women. Journal of Clinical Psychology, 10(1), 47-56. (Persian). [Link]

Pakenham, K. I., Landi, G., Boccolini, G., Furlani, A., Grandi, S., \& Tossani, E. (2020). The moderating roles of psychological flexibility and inflexibility on the mental health impacts of COVID-19 pandemic and lockdown in Italy. Journal of contextual behavioral science, 17, 109-118. [Link]

Petersen. C., L. \& Zettle, R. D. (2009). Treating Inpatients with Comorbid Depression and Alcohol Use Disorders: A Comparison of Acceptance and
Commitment Therapy versus Treatment as Usual. The Psychological Record, 2009, 59, 521-536. [Link]

Rahimi Movaghar, A., Malayerikhah Langroodi, Z., Delbarpour Ahmadi, S., \& Amin Esmaeili, M. (2011). A Qualitative Study of Specific Needs of Women for Treatment of Addiction. Iranian Journal of Psychiatry and Clinical Psychology, 17 (2), 116-125. (Persian). [Link]

Ramaci, T., Bellini, D., Presti, G., \& Santisi, G. (2019). Psychological Flexibility and Mindfulness as Predictors of Individual Outcomes in Hospital Health Workers. Frontiers in psychology, 10, 1302. [Link]

Sadeghi Fasaei, S., \& Jahandar lashaki, Z. (2020). A Qualitative Study of Addiction in Women. Journal of policing \& social studies of women \& family, 8(1), 24-43. (Persian). [Link]

SAMHSA (2012). Model Programs. Effective Substance Abuse and Mental Health Programs for Every. Available from: http://modelprograms.samhsa.gov [retrieved 7 Oct 2013] [Link]

Sharifi, P., Mousavi, S. A., \& Hasani, J. (2018). The Discriminational Role of Reinforcement sensitivity theory, Emotion Regulation Processes Strategies and Cognitive Flexibility in Discrimination of People with Internet Addiction. Journal of Cognitive Psychology, 6(2), 51-60. (Persian). [Link]

Shokri, L., \& Mehri Nia, F. (2020). Effectiveness of self differentiation training on psychological resilience and feeling entrapment in the mothers of the children with attention deficit and hyperactivity disorder (ADHD). The Journal of Psychological Science, 19(92), 1031-1040. (Persian). [Link]

Smith, B.M., Smith, G., \& Dymond, S. (2019). Relapse of anxiety-related fear and avoidance: Conceptual analysis of treatment with acceptance and commitment therapy. Journal of the experimental analysis of behavior. 113(1), 7- 104. [Link]

Sohrabi, F., Mamsharifi, P., Rafezi, Z., \& A'azami, Y. (2019). Predicting Addiction Potential based on Mental Health, Social Support and Neuroticism and Agreeableness Personality Traits. Iranian Journal of Psychiatric Nursing. 6 (6), 57-66. (Persian). [Link]

Stotts, A. L., Masuda, A., \& Wilson, K. (2009). Using Acceptance and Commitment Therapy during Methadone Dose Reduction: Rationale, Treatment Description, and a Case Report. Journal of school Health. 16(2), 205-213. [Link] 
Thurstone, C., Hull, M., Timmerman, J., \& Emrick, C. (2017). Development of a motivational interviewing/acceptance and commitment therapy model for adolescent substance use treatment. Journal of Contextual Behavioral Science, 6(4), 375-379. [Link]

Wang, S., Zhou, Y., Yu, S., Ran, L.-W., Liu, X.-P., \& Chen, Y.-F. (2017). Acceptance and Commitment Therapy and Cognitive-Behavioral Therapy as Treatments for Academic Procrastination: A Randomized Controlled Group Session. Research on Social Work Practice, 27(1), 48-58. [Link]

Watts, R., \& Luoma, J. (2020). The use of the psychological flexibility model to support psychedelic assisted therapy. Journal of contextual behavioral science, 15, 92-102. [Link]

Wynne, B., McHugh, L., Gao, W., Keegan, D., Byrne, K., Rowan, C., Hartery, K., Kirschbaum, C., Doherty, G., Cullen, G., Dooley, B., \& Mulcahy, H. E. (2019). Acceptance and Commitment Therapy Reduces Psychological Stress in Patients with Inflammatory Bowel Diseases. Gastroenterology, 156(4), 935-945.e1. [Link]

Zandkarimi, G., \& Ramezan, M. (2018). Comparision the Meta-Cognition, Cognitive Flexibility and Focus Attention between Metamphetamine Addicted and Normal People. Journal of Psychological Studies, 13(4), 59-75. (Persian). [Link] 